\title{
Bladder cancer among French farmers: does exposure to pesticides in vineyards play a part ?
}

\author{
Jean-François Viel, Bruno Challier
}

\begin{abstract}
Objective-To appraise the potential contribution of pesticides sprayed on vineyards to the genesis of bladder cancer among agricultural workers.

Methods-A pesticide exposure index (PEI), based on labour time and the proportion of agricultural land used as vineyards, was constructed for 89 French geographical units (départements). The standardised mortality ratios (SMRs) for bladder cancer, as well as tobacco consumption and economic status of male farmers and farm labourers aged 35-74 in the same areas were estimated for the period 1984-6. Models were fitted to the geographical data with Poisson regressions and extra-Poisson models with geographically structured and unstructured random effects.
\end{abstract}

Results-Mortality from bladder cancer among farmers was lower (but not significantly so) than within the overall population (SMR 0.96, 95\% confidence interval (95\% CI) $0.85-1.08)$, but there was a significant link with exposure to pesticides in vineyards by univariate analysis (relative risk (RR) $1 \cdot 17,95 \%$ CI $1 \cdot 10-1 \cdot 24)$ and by multivariate analysis (RR 1·14, 95\% CI 1·07-1·22).

Conclusion-These results add some evidence to the view that pesticides in vineyards cause mortality from bladder cancer among farmers, and could explain the French south-north gradient in bladder cancer, as vineyards are mainly located in Southern France.

(Occup Environ Med 1995;52:587-592)

Key words: bladder cancer, farmers, pesticides

Exposure to several potential health hazards is typical of farmers (farm machinery, zoonotic viruses, chemical products). In France, 700 000-1000 000 people (farm workers, applicators, manufacturers, formulators, packers) are potentially exposed to the 93000 tonnes of pesticides (insecticides, herbicides and fungicides) that are used every year. ${ }^{1}$ Overall mortality and mortality from cancers have generally been reported as lower among farmers than within the whole population ${ }^{2}$ although there is some evidence of a higher risk of certain types of cancer in agriculture. ${ }^{3}$

Bladder cancer, for instance, is a major concern for French farmers for several reasons. First, restriction of the study to this population, that includes fewer smokers than the overall population, allows the assessment of potential risk factors without the confounding effect of smoking, which is well documented. ${ }^{4}$ Secondly, mortality from bladder cancer in France shows a south-north gradient that is higher in the south, and vineyards are mostly located in the southern areas. Furthermore, biochemistry could explain the potential danger from pesticides in this group. Aromatic amines, for instance, are used as intermediates in the manufacture of pesticides, and a relation to bladder cancer has been found in the past for this group of chemicals in the dyestuffs industry. ${ }^{4}$

Among eight proportionate mortality or morbidity studies that found a lower risk of bladder cancer in farmers and farm labourers, four had significant ratios: one Swedish study (standardised incidence ratio (SIR) $0.64,95 \%$ confidence interval (95\% CI) 0.59-0.69), ${ }^{5}$ one British (proportionate mortality ratio (PMR) $0.82, \mathrm{P}<0.01),{ }^{6}$ and two United States surveys: California (proportionate cancer mortality ratio (PCMR) $0.60, \mathrm{P}<0.01)^{7}$ and Wisconsin (PMR 0.88, $\mathrm{P}<0.05) .{ }^{8}$ Four others did not find significant results in Canada, ${ }^{9}$ North Carolina, ${ }^{10}$ Switzerland, ${ }^{11}$ and Iceland, ${ }^{12}$ whereas one study in Iowa reported a higher risk (standardised mortality ratio (SMR) 1.14, $\mathrm{P}<0.01) .{ }^{13}$ Furthermore, a Swedish cohort study on agricultural workers reported a significantly decreased risk. ${ }^{14}$ One reason for this generally reduced risk could be the lower tobacco consumption in farmers and farm labourers, compared with the overall population.

Some case-control studies of bladder cancer provide evidence in favour of the pesticide exposure hypothesis. Male insecticide users in Alberta (odds ratio (OR) $1.67, \mathrm{P}<0.05)^{15}$ and chemicals users in Ottawa (OR 1.50, P < $0.05),{ }^{16}$ Italian male pesticide users in the fruit growing industry (OR 3.97, $\mathrm{P}<0.05),{ }^{17}$ and Italian herbicide users (OR $4 \cdot 1, \mathrm{P}<$ $0.01)^{18}$ all seemed to be populations at risk. Other case-control studies found no evidence of higher risk of bladder cancer for farmers in the United States, ${ }^{19-22}$ Canada, ${ }^{23}$ Italy, ${ }^{24}$ Spain, ${ }^{25}$ Germany, ${ }^{26}$ and New Zealand. ${ }^{27}$ Nevertheless, one particular study in the United States found significantly raised OR estimates for farmers within a population of non-smoker Seventh Day Adventists (OR 9.7, $P<0.05),{ }^{28}$ which supports the possibility that exposure to pesticides causes bladder cancer that cannot be attributed to tobacco consumption in this particular group. 
Overall, these conflicting results show that the topic is still of interest, but needs further evidence. The proportionate mortality or morbidity studies often mentioned exposure to pesticides as the potential cause of cancer, but in case-control studies where pesticides were better quantified, results were no more conclusive. Indeed, assessing agricultural exposure to pesticides is complex, and can either be done at an individual level or at a geographical level. Individual measures seem better adapted to assess the exposure among manufacturing plant workers than among farmers, and the geographical indices of exposure that rely on production of specified crops, the number of acres treated with pesticides, etc, are only indirect indicators. Nevertheless, a measurement of exposure to pesticides can be attempted at a geographical level. ${ }^{29}$ The purpose of this study was to investigate, at an ecological level, the relation between bladder cancer and exposure to pesticide in vineyards.

\section{Material and methods}

STUDY POPULATION

The investigated population consisted of male farmers and farm labourers aged 35-74. This age range was chosen because too few deaths occurred before the age of 35 , and death certificates were too imprecise for occupational analysis over 74. Eighty nine statistical units called départements (French administrative areas averaging 600000 inhabitants) were used. Five départements were excluded because agricultural activity in them was too low. For this group, we obtained the number of deaths due to bladder cancer (code 188 in the ninth revised International Classification of Diseases (ICD-9)) that occurred during the years 1984-6. This information was collected from the French National Medical Research Institute (INSERM). Census data (1975 and 1982) and extrapolations for the years 1984-6 were obtained for each département from the French Office of Population Censuses (INSEE).

\section{ASSESSMENT OF EXPOSURE}

Exposure to pesticides was assessed at a geographical level for farmers and farm labourers in vineyards with a measurement called pesticide exposure index (PEI), fully described elsewhere. ${ }^{29}$

The agricultural census of $1970^{30}$ provides information on the numbers of agricultural workers and the amount of time they work, enabling the calculation for such départements of the LYP (labour $\times$ year $\times$ person) in units of full time workers. One unit represents 40 hours a week for 275 days or more per year.

The PEI is computed as the product of the LYP and the proportion of agricultural land used as vineyards (PAL, also derived from the 1970 agricultural census) divided by the total agricultural worker population (POP) aged 35-74, derived from the next annual census (in 1975).
PEI = LYP $\times$ PAL $/$ POP (farmers: 35-74)

As the agricultural census of 1970 and the national census attempted to identify the same population, the ratio of LYP to agricultural workers in 1975 was introduced as a measure of the extent to which workers identified by census are engaged in agricultural work.

A time delay between exposure (1970-5) and mortality (1984-6) was therefore to some extent accounted for

\section{STATISTICAL ANALYSIS}

Cancer mortality among farmers and farm labourers, for the years 1984-6, was expressed as SMRs of observed to expected deaths, which provide age adjusted comparative risks. To compute expected deaths for each département, national rates from the entire male population for the same years, were applied to the person-years of each area stratified by the same 10-year age classes used for mortality and census data. Confidence intervals were based on the Poisson distribution. ${ }^{31}$

Models were fitted to the grouped data with, in a first step, Poisson regression analysis. Statistical units are, as already explained, départements for which logarithms of observed and expected deaths were linked with a set of covariate values, in a linear model that accounted for Poisson errors.

The farmers' economic status was considered as a potential confounding variable, and introduced into the model by including a variable that recorded the percentage of farms in each département with a standard gross profit margin greater than 16000 European currency units. Tobacco consumption was assessed by the sales of tobacco in each département in 1953.

The Poisson model equation is :

$$
\log \left(O_{i}\right)=\log \left(E_{i}\right)+\mu+x_{i} \beta
$$

in which:

$i=1$ to $89 ; O_{i}=$ observed number of deaths; $E_{i}=$ expected number of deaths (age adjusted); $\mu=$ grand mean-that is, log $(\mathrm{SMR})$ for the unexposed $\left(x_{i}=0\right) ; x_{i}=\left(x_{i}^{(1)} \ldots\right.$ $\left.x_{i}{ }^{(3)}\right)$ three dimensional row vector of regression variables (PEI, standard gross profit margin, tobacco consumption); $\beta=\left(\beta_{1}, \ldots, \beta_{3}\right)$, three dimensional column vector of regression coefficients.

In a second step we used an approach originally developed by Clayton et $\mathrm{al}^{32}$ to model the covariate effect in the presence of both unstructured and geographically autocorrelated extra-Poisson variations. This extraPoisson regression model may be written as follows :

$$
\log \left(O_{i}\right)=\log \left(E_{i}\right)+\mu+x_{i} \beta+\varepsilon_{i}^{(I)}+\varepsilon_{i}^{(2)}
$$

The first component of variation, $\varepsilon_{i}^{(l)}$ is the spatially unstructured extra-Poisson variation, called heterogeneity by Clayton et al. These random effects are independent and normally distributed. The second component of variation varies smoothly across areas, and was called clustering. These random effects are normally distributed, with mean given by the 
mean of geographically adjacent neighbouring, $\varepsilon_{i}^{(2)}$. Hence the fitted OR can be separated into its three multiplicative components:

- that due to the explanatory variables: $\exp \left(\beta x_{\mathrm{i}}\right)$,

- heterogeneity : $\exp \left(\varepsilon_{i}^{(1)}\right)$,

- clustering : $\exp \left(\varepsilon_{i}^{(2)}\right)$.

One may notice that when the random effects are not included in the model, it is simply a Poisson regression.

In both models, estimates of relative risks (RR) for the independent variables are provided by $\exp (\beta)$. Dose-response trends are assessed by tests of significance of regression coefficients for variables that represent quantitative levels of exposure. To interpret how the risk of mortality changes with these continuous scaled covariates, ORs are reported for the upper exposure quartiles, with the lowest quartiles as control groups with their corresponding $95 \%$ CIs.

All these analyses were performed with EGRET $^{33}$ or BEAM ${ }^{34}$ software.

\section{Results}

The study population consisted of 837413 male farmers or farm labourers, aged 35-74 (followed up for three years). The PEI ranged from 0 to 0.212 (mean (SD) $0.030(0.052)$ ), standard gross profit margin greater than 16000 European currency units from $2 \cdot 8 \%$ to $67 \cdot 3 \%$ (mean (SD) $21 \cdot 0 \%(14 \cdot 8 \%)$ ), and tobacco consumption from 1221 to 2534 $\mathrm{g} /$ inhabitant/y (mean (SD) 1707 (266.3)).

Overall mortality from bladder cancer was similar to the national norm, with an SMR of 0.96 (95\% CI 0.85-1.08); a trend across PEI quartiles was noticeable as the SMRs ranged from 0.71 for the lowest quartile, to 1.23 for the upper one (table 1 ). Table 2 shows the relative risk estimates for exposure to pesticides in vineyards, adjusted or not for confounding factors in Poisson regression models. Mortality from bladder cancer

Table 1 Mortality from bladder cancer in French farmers and farm labourers aged 35-74 (1984-6)

\begin{tabular}{llccc}
\hline Quartiles & $\begin{array}{l}\text { PEI median } \\
\text { exposures }\end{array}$ & $\begin{array}{l}\text { Observed } \\
\text { deaths }\end{array}$ & $\begin{array}{l}\text { Expected } \\
\text { deaths }\end{array}$ & SMR† \\
\hline 1 & 0 & 64 & 90.0 & 0.71 \\
2 & 0.003 & 52 & 53.0 & 0.98 \\
3 & 0.027 & 57 & 61.1 & 0.93 \\
4 & 0.151 & 102 & 82.6 & 1.23 \\
Total & & 275 & 286.7 & 0.96 \\
\hline
\end{tabular}

«Expected number of deaths, based on national age specific mortality rates for French males, 1984-6.

Table 2 Estimates of relative risk of bladder cancer from Poisson regression analyses on French farmers and farm labourers (1984-6)

\begin{tabular}{llc}
\hline Model & $R R(95 \%$ CI $)$ & $P$ value \\
\hline PEI (univariate analysis) & $1 \cdot 17(1 \cdot 10-1 \cdot 24)$ & $<10^{-6}$ \\
PEI (multivariate analysis): & $1 \cdot 14(1 \cdot 07-1 \cdot 22)$ & $<10^{-3}$ \\
Standard gross profit margin & $0.76(0.51-1 \cdot 13)$ & $0 \cdot 17$ \\
Tobacco consumption & $1 \cdot 21(0.88-1 \cdot 65)$ & 0.24 \\
\hline
\end{tabular}

Risk estimates for quantitative exposures are reported for the upper exposure quartiles, with the lowest quartiles as control groups.
Table 3 Estimates of relative risk of bladder cancer from correlation tests between geographically correlated variables

\begin{tabular}{|c|c|c|}
\hline Model & $R R(95 \% C I)$ & $P$ value \\
\hline $\begin{array}{l}\text { PEI: } \\
\text { Heterogeneity } \\
\text { Clustering }\end{array}$ & $\begin{array}{l}1 \cdot 16(1 \cdot 08-1 \cdot 25) \\
-\quad-\end{array}$ & $\begin{array}{l}0.002 \\
0.14 \\
0.04\end{array}$ \\
\hline $\begin{array}{l}\text { PEI: } \\
\text { Standard gross profit margin } \\
\text { Tobacco consumption } \\
\text { Heterogeneity } \\
\text { Clustering }\end{array}$ & $\begin{array}{l}1.14(1.06-1 \cdot 23) \\
0.76(0.51-1.14) \\
1.20(0.84-1.70) \\
-\quad=\end{array}$ & $\begin{aligned}<10^{-3} \\
0 \cdot 18 \\
0 \cdot 32 \\
0.04 \\
0 \cdot 17\end{aligned}$ \\
\hline
\end{tabular}

Risk estimates for quantitative exposures are reported for the upper exposure quartiles, with the lowest quartiles as control groups.

showed a significant association with PEI in a univariate analysis $\left(\mathrm{RR} 1 \cdot 17, \mathrm{P}<10^{-6}\right)$, and in a multivariate analysis ( $R R 1 \cdot 14, P<10^{-3}$ ). In the multivariate analysis the farmers' economic status seems to be protective, although not significantly ( $R R 0 \cdot 76, P=0 \cdot 17$ ), and tobacco consumption is a non-significant risk factor (RR $1 \cdot 21, \mathrm{P}=0 \cdot 24)$.

Table 3 shows results obtained from extraPoisson models. They were similar to those derived from the simple Poisson regression models. The PEI was still a significant risk factor, in both the univariate and multivariate analyses ( RR 1.16, $P=0.002 ; R R 1 \cdot 14, P<$ $\left.10^{-3}\right)$. The confounding factors showed the same non-significant patterns as in the Poisson regression model ( $R R 0 \cdot 76, P=0 \cdot 18$; RR $1 \cdot 20, P=0 \cdot 32$, for standard gross profit margin and tobacco consumption, respectively). In the univariate analysis, a significant clustering random effect was highlighted $(P=$ 0.04 ), whereas in the multivariate model a significant random heterogeneity was present $(P=0.04)$.

\section{Discussion}

Investigation of the pattern of mortality from bladder cancer showed no increase among farmers and farm labourers. Nevertheless, a significant link with PEI in vineyards was found in a univariate as well as in a multivariate analysis, after adjustment for economic status and tobacco consumption.

Geographical studies are a natural design for the study of an environmental factor, as they are less prone than individual epidemiological studies to the effects of random error in the measurement of exposure. ${ }^{35}$ Hence, they can represent an alternative design to highlight the influence of pesticide exposure on cancer mortality. ${ }^{29}$

One must keep in mind the difficulty of ensuring comparability within occupational groups of data from death certificates and from a census, which rely on the accuracy of the "usual occupation" stated by relatives of deceased patients. ${ }^{4}$ The deaths of the people at risk, active farmers and farm labourers, must be recorded within the same population. Problems could arise for the age range 65-74 if some retired farmers were declared as still active. Unfortunately, to our knowledge no specific survey has yet been conducted to investigate this potential bias, probably for 
legal reasons. In France, mortality records are anonymous, and until now no linkage is allowed between individual mortality data and other data.

One can only remark that: (1) although the occupational categories are often broad, in this particular case they were sufficiently specific to characterise the population of farmers and the farm labourers without ambiguity, and to separate them from the population of retired farmers - census and death certificates were coded with the same INSEE French nomenclature. ${ }^{36}$

(2) This study was concerned with comparisons between populations within each département, so if a bias occurred, as it was more or less the same in each département, then the association should not be distorted in a major way.

There is as yet no national cancer incidence registry in France, so we studied mortality, which at least is not affected by the variations in completeness and accuracy of registration of cancer data. In France coding and registration of deaths are done at a national level. As this study used comparisons between populations within each département, association of bladder cancer and PEI should not have been affected, provided the incidence and mortality ratios were similar for all départements.

As in any geographical study, this one could be subject to ecological fallacy - that is, the relation between exposure and disease in groups is not necessarily the same as that in individual people. Ecological fallacy is more likely to occur when populations or geographical units are broad, when exposure is recorded at the same time as the deaths (and sometimes after), or when the accuracy of the exposure measurement is questionable. To minimise this effect five non-agricultural départements were excluded, the study population was restricted to male farmers and farm labourers (those most exposed to pesticides ${ }^{37}$ ), there was a time lag between exposure and mortality, exposure on a geographical level was carefully assessed (each term of the numerator in the PEI estimates the agricultural labour time devoted to vine growing), spatial autocorrelation was accounted for, and potential confounding factors were included in the models.

Nevertheless, this ecological study still has some limitations. Firstly, it does not focus on vine farmers but on all farmers. The French two digit classification used (as well as the more accurate four digit definition that mixes orchards and vine farmers) made us unable to distinguish vine growers from other farmers. Secondly, the 10-15 year difference in time between ascertainment of PEI and ascertainment of death introduces a rather short lag period. No major change in agricultural practices, however, had occurred in France between the 1960s and 1970s (as opposed to the period 1970-80). Thirdly, the LYP estimates also include farmers aged 35 years or less (who represent $18 \%$ of the total), but this proportion, quite stable across départements, should not distort the association.
The major determinant of the PEI is the proportion of usable agricultural land devoted to vineyards, and the question of whether a vineyard exposure index (VEI) is similar to a PEI needs to be answered. Farmers are exposed to many other health hazards and if these were implicated, other farming would also be associated with bladder cancer, which is not the case. In a previous paper we have established a similar index to estimate the exposure of farmers in arable land that also takes into account the frequency of pesticide treatment of the five most intensively treated crops (cereal, sugar beets, maize, oil seed rape, potatoes). ${ }^{38}$ We have then highlighted a significant association between this exposure and leukaemia mortality among farmers. When crossing pesticide exposures and cancer subtypes (bladder cancer and arable land exposure on the one hand, leukaemia and vineyard exposure on the other), no association turned out to be significant (results not shown). Regional differences in the amount of pesticide application on vineyards (types or methods of application are quite similar) would also make the equation VEI = PEI questionable. It would have seemed conceivable that, given different climates, there would be a south-north difference in use of pesticides in vineyards. If such regional differences can occur, however, they are not related to climatic conditions but to the variety of vine and also to vine farmers' incomes. It is well known that vine growers from Champagne or Burgundy spread greater amounts of pesticides on their vineyards than their colleagues from the Mediterranean areas, because they can afford it. This is one more reason to introduce farmers' incomes as a confounding factor in the Poisson regression model, as we did.

The extra-Poisson variation model seems to be an attractive tool to deal with data collected at an area level. It represents a way of allowing for unmeasured variables that differ between areas in an unstructured manner (random heterogeneity), and for unmeasured risk factors that vary locally (clustering random effect). Hence, deviations from Poisson distribution and spatial autocorrelation were taken into account in this model. In our study, as the link between PEI and mortality from bladder cancer was strong, to add the random effects hardly changed the strength of the association. The clustering effect, present in the univariate analysis, did not remain in the multivariate analysis, which shows the random heterogeneity. This probably came from the fact that the identified confounding factors (economic status and tobacco consumption) could explain part of the smooth geographical variation in the unmeasured variables, whereas some unstructured extraPoisson variation still remains in the multivariate model.

One potential drawback of the method lies in its conservatism when the clustering term is included. If location (which in fact is a surrogate for any unmeasured confounding factor) acts as a confounder, then the model 
will over-correct upon introduction of the clustering term, ${ }^{32}$ yielding attenuated regression estimates. This disadvantage was not found in this study, which indicates that the covariate effect was not seriously altered by the effect of location.

Clearly, as with any geographical analysis, one has to be cautious when interpreting the statistical regression coefficients. We took into account two types of confounders, a socioeconomic factor (a complex indicator that could represent both health access and other factors connected with standard of living) and tobacco consumption (that is a surrogate for tobacco smoking) that has been strongly implicated as a cause of bladder cancer. Ideally, tobacco consumption data relating to the relevant group (farmers and farm labourers) should have been used, but unfortunately these data were missing (to our knowledge no data focusing on tobacco consumption of vine farmers are available, even for the whole country). Furthermore, not only the marginal distributions but also the (missing) joint exposure distributions would have been helpful to make those analyses less prone to confounding, even if random terms partly solved this problem.

The findings of this study lead us to think that pesticides used in vineyards affect mortality from bladder cancer. This has been kept hidden by the low prevalence of tobacco smoking among farmers.

Two reasons could explain this relation, intensity of exposure (to any one pesticide), and the nature of one or more substances more specifically sprayed on vines rather than on other crops. The facts that lead us to think that the first of these two hypotheses is correct are: in France vine growing takes place on only $10 \%$ of all the arable land, but uses $80 \%$ of all the herbicides and $46 \%$ of all the insecticides used, ${ }^{1}$ vine protection requires three types of pesticides $(80 \%$ of the total vine growing surface is treated with herbicides, $82 \%$ with insecticides, and $100 \%$ with fungicides $^{1}$ ), the spraying of these pesticides has been and is sometimes still done manually (knapsack spraying), when this spraying is automatic it is performed under high pressures with spray booms mounted on a tractor, to allow the pesticides to reach the grapes under the leaves. This technique, spraying under high pressure, induces a large diffusion of the toxic substances, hence a potentially strong exposure.

Supporting the second hypothesis, it seems that among the pesticides used on vines, some are (more or less) specific to vines, ${ }^{39}$ herbicides (simazin and diuron, which have a long lasting effect in the ground), fungicides (dithiocarbamates and phthalimids, classified by the United States National Academy of Sciences among the most potentially carcinogenetic substances ${ }^{40}$ ), and nematocides (dichloropropene, a ground fumigant with toxicity classified as moderate that could be intensified by the particular way it is used).

Furthermore, great amounts of copper sulphate (the main compound of the "Bordeaux mixture") are sprayed over vineyards, and could also play a part.

Our results add some evidence to the view that pesticides used in vineyards could affect mortality from bladder cancer among farmers, and could explain the French south-north gradient in bladder cancer, as vineyards are mostly located in southern France. Further individual investigations, with biochemical indicators, and focusing on the chemical compounds suspected in this study, are clearly needed. We must bear in mind that the chances of showing precise effects of pesticides on health are certainly decreasing as agricultural practices grow safer.

We thank one referee for making constructive comments that substantially improved this paper; Sylvia Richardson for her methodological assistance at the beginning of this work; and David Clayton for kindly providing BEAM Software.

1 Delemotte B, Foulhoux P, Nguyen SN, Fages J, Portos JL. The pesticide hazard in agriculture. Arch Mal Prof 1987; 48:467-75. (In French.)

2 Wiklund $K$. Swedish agricultural workers. A group with a decreased risk of cancer. Cancer 1983;51:566-8.

3 Blair A, Malker H, Cantor KP, Burmeister L, Wiklund K Cancer among farmers: a review. Scand $\mathcal{f}$ Work Environ Health 1985;11:397-407.

4 Tomatis L. Cancer: causes, occurences and control. Lyon International Agency for Research on Cancer, 1990. (IARC Sci Publ No 100.)

5 Vågerö $\mathrm{D}$, Persson $\mathrm{G}$. Occurrence of cancer in socioeconomic groups in Sweden. Scand f Soc Med 1986;14: 151-60.

6 Adelstein AM. Occupational mortality: cancer. Ann Occup Hyg 1972;15:53-7.

7 Stubbs HA, Harris J, Spear RJ. A proportionate mortality analysis of California agricultural workers, 1978-1979. Am $₹$ Ind Med 1984;6:305-20.

8 Saftlas AF, Blair A, Cantor KP, Hauranan L, Anderson Saftlas AF, Blair A, Cantor KP, Hauranan L, Anderson
HA. Cancer and other causes of death among Wisconsin farmers. Am f Ind Med 1987;11:119-29.

9 Gallagher RP, Threlfall WJ, Jeffries E, Band PR, Spinelli J, Coldman AJ. Cancer and aplastic anemia in British Columbia farmers. $\mathcal{F}$ Natl Cancer Inst 1984;72:1311-5.

10 Delzell E, Gruffermann S. Mortality among white and nonwhite farmers in North Carolina, 1976-1978. Am Epidemiol 1985;121:391-402.

11 Levi F, Negri E, La Vecchia C, Te VC. Socioeconomic groups and cancer risk at death in the Swiss canton of groups and cancer risk at death in th.

12 Rafnsson V, Gunnarsdótir H. Mortality among farmers in Iceland. Int $\mathcal{F}$ Epidemiol 1989;18:146-51.

13 Burmeister LF Cancer mortality in Iowa farmers, 1971-1978. F Natl Cancer Inst 1981;66:461-4.

14 Wiklund $\mathrm{K}$, Holm LE. Trends in cancer risks among Swedish agricultural workers. F Natl Cancer Inst 1986; 77:657-64.

15 Fincham SM, Hanson J, Berkel J. Patterns and risks of cancer in farmers in Alberta, Canada. Cancer 1992;69. 1276-85.

16 Miller CT, Neutel CI, Nair RC, Marrett LD, Last JM, Collins WE. Relative importance of risk factors in bladder carcinogenesis. F Chron Dis 1978;31:51-6.

17 Forastiere F, Quercia A, Miceli M, Settimi L, Terenzoni $\mathrm{B}$, Rapiti $\mathrm{E}$ et al. Cancer among farmers in Central Italy. B, Rapiti E et al. Cancer among farmers in Cent

18 La Vecchia C, Negri E, d'Avanzo B, Franceschi S Occupation and the risk of bladder cancer. Int $\dot{f}$ Epidemiol 1990;19:264-8.

19 Blair A, Watts D. Bladder cancer and dairy farming. f Occup Health 1980;22:576-7.

20 Williams RR, Stegens NL, Goldsmith JR. Association of cancer site and type with occupation and industry from the third national cancer survey interview. $\mathcal{f}$ Natl Cancer Inst 1977; 59:1147-85.

21 Silverman DT, Hoover RN, Albert S, Graff KM Occupation and cancer of the lower urinary tract in Detroit. $\mathcal{F}$ Natl Cancer Inst 1983;70:237-45.

22 Schoenberg JB, Stemhagen A, Mogielnicki AP, Altman R, Abe T, Mason TJ. Case-control study of bladder cancer in New Jersey. Occupational exposures in white males. $₹$ Natl Cancer Inst 1984;72:973-81.

23 Howe GR, Burch JD, Miller AB, Cook GM, Esteve J, Morrison B, et al. Tobacco use, occupation, coffee, Morrison $\mathrm{B}$, et al. Tobacco use, occupation, coffee,
various nutrients, and bladder cancer. $\mathcal{f}$ Natl Cancer Inst various nutrients,

24 Vineis P, Magnani C. Occupation and bladder cancer in males: a case-control study. Int $f$ Cancer 1985;35: 599-606.

25 Gonzales CA, Lopez-Abente G, Errezola M, Escolar A, Riboli E, Izarzugaza I, Nebot M. Occupation and bladder cancer in Spain: a multi-centre case-control study. Int $\mathcal{F}$ Epidemiol 1989;18:569-77. 
26 Claude JC, Frentzel-Beyme RR, Kunze E. Occupation and risk of cancer of the lower urinary tract among men. A case-control study. Int $₹$ Cancer 1988;41:371-9.

27 Reif J, Pearce N, Kawachi I, Fraser J. Soft-tissue sarcoma, non-Hodgkin's lymphoma and other cancers in New Zealand forestry workers. Int $\mathcal{F}$ Cancer $1989 ; 43: 49-5$

28 Kabat GC, Dieck GS, Wynder EL. Bladder cancer in nonsmokers. Cancer 1986;57:362-7.

29 Viel JF, Richardson ST. Adult leukemia and farm practices: an alternative approach for assessing geographical pesticide exposure. Soc Sci Med 1991;32:1067-73.

30 Ministry of Agriculture. General agricultural census 1970-71. Results for overall France. Paris: Service Central des Enquêtes et Etudes Statistiques, 1972. (In French.)

31 Morris JA, Gardner MJ. Calculating confidence intervals for relative risks, odds ratios and standardized ratios and risks. In: Gardner MJ, Altman DG, eds. Statistics with risks. In: Gardner MJ, Altman DG, eds. Statistics with
confidence-confidence intervals and statistical guidelines. confidence-confidence inter

32 Clayton DG, Bernardinelli L, Montomoli C. Spatial correlation in ecological analysis. Int $\mathcal{F}$ Epidemiol 1993;22: 1193-202.

33 EGRET. Seattle: Statistics and Epidemiologic Research Corporation, 1990

34 Clayton D, Bernardinelli L. Bayesian methods for mapping disease risk. In: Elliott P, Cuzick J, English D,
Stern $\mathrm{R}$, eds. Geographical and environmental epideStern R, eds. Geographical and environmental epidemiology: methods for small area

35 English D. Geographical epidemiology and ecological studies. In: Elliott P, Cuzick J, English D, Stern R, eds. Geographical and environmental epidemiology: methods for small area studies. Oxford: Oxford University Press, 1992:3-13.

36 INSEE. Nomenclature of occupations and socio-professionnal categories. Anal

37 Davies JE. Epidemiologic concerns for exposure assessment. In: Siewierski M, ed. Determination and assessment of pesticide exposure. Studies in environmental science. New pesticide exposure. Studies in

38 Viel JF, Richardson ST. Lymphoma, multiple myeloma and leukaemia among French farmers in relation to pesticide exposure. Soc Sci Med 1993;37:771-7.

39 Fougeroux A, Bourdet $M$. Phytosanitary substances. Evaluation of surfaces and weights for each type of treatment in 1988. La Défense des Végétaux 1989;259:3-8. (In French.)

40 US National Academy of Sciences. Regulating pesticides in food. Washington DC, 1987. 